\title{
THE ASSOCIATION BETWEEN SOCIOECONOMIC FACTORS AND SELECTION OF BIRTHPLACE IN PREGNANT WOMEN
}

\author{
Silfia Angela Norce Halu, Maria Sriana Banul
}

Diploma of Midwifery, School of Health Sciences Santu Paulus

\begin{abstract}
Background: Childbirth and the culture surrounding it are powerful dimensions of human society. Birthplace is an important component of birth, which can include physical, emotional, cultural and social aspects. Women make birthplace decisions within their socio-political and cultural context, which adds to its complexity. This study aimed to examine the association between socioeconomic factors and selection of birthplace in pregnant women.

Subjects and Method: A cross sectional study was conducted at 6 puskesmas (Community Health Centers) in Pota, Manggarai, East Nusa Tenggara. A sample of 59 pregnant women was selected for this study. The dependent variable was selection of birthplace (home versus hospital). The independent variables were maternal education, employment, family income, decision maker, and travel time. The data were collected by questionnaire and analyzed by a multiple logistic regression.

Results: The choice of hospital as the birthplace was associated with high maternal education $(\mathrm{OR}=4.51 ; \mathrm{p}=0.020)$, being employed $(\mathrm{OR}=2.75 ; \mathrm{p}=0.040)$, high family income $(\mathrm{OR}=4.77 ; \mathrm{p}<0.001)$, maternal shares the decision making $(\mathrm{OR}=3.12 ; \mathrm{p}=0.030)$, and short travel time $(\mathrm{OR}=4.45 ; \mathrm{p}=0.001)$.

Conclusion: The choice of hospital as the birthplace is associated with high maternal education, being employed, high family income, maternal shares the decision making, and short travel time.
\end{abstract}

Keywords: socioeconomic factor, birthplace, pregnant women.

\section{Correspondence:}

Silfia Angela Norce Halu. Diploma of Midwifery, School of Health Sciences Santu Paulus, Manggarai, East Nusa Tenggara. Email: occe.halu@gmail.com.

Mobile: 081259163953. 